\title{
Uso de enzimas em dietas contendo níveis crescentes de farelo de arroz integral para frangos de corte
}

\author{
Use of enzymes in diets containing increasing levels of whole rice meal for broilers
}

\author{
Elivelton Luiz Bonato ${ }^{1}$ Irineo Zanella ${ }^{2}$ Ricardo dos Santos ${ }^{3}$ Sandra Paula Gasparini ${ }^{4}$ \\ Leandro Magon ${ }^{3}$ Alexandre Pires Rosa ${ }^{2}$ Lourdes Padilha Brittes ${ }^{5}$
}

\section{RESUMO}

\begin{abstract}
$O$ experimento foi realizado com o objetivo de determinar o desempenho e o rendimento de carcaça de frangos de corte alimentados com dietas contendo níveis crescentes de farelo de arroz integral (FAI), suplementadas ou não com enzimas. Foram utilizados 960 pintos de corte, machos e fêmeas da linhagem Cobb distribuídos em um delineamento experimental inteiramente casualizado, com oito tratamentos e seis repetições de 20 aves. Utilizaram-se 4 níveis de FAI $(0 \%, 10 \%, 20 \%$ e $30 \%)$, com e sem suplementação de um complexo multienzimático composto pelas enzimas protease, pentosanase e fitase. As dietas experimentais foram isoenergéticas, isoproteicas, isofosfóricas e isocálcicas para todos os tratamentos. Com a utilização de níveis crescentes de farelo de arroz integral, houve redução significativa $(P<0,01)$ no consumo de ração, no peso corporal e no ganho de peso das aves, no entanto, a conversão alimentar não foi afetada. $O$ peso do peito, rendimento de peito, peso da carcaça e peso de coxa também foram influenciados significativamente $(P<0,01)$ pelos niveis de adição de farelo de arroz integral na dieta. $O$ uso de enzimas não influenciou significativamente $(P>0,05)$ nenhum dos parâmetros avaliados, entretanto, as rações suplementadas com o complexo multienzimático, promoveram um índice bio-econômico (IBE) 1,4\% superior em relação às dietas não suplementadas.
\end{abstract}

Palavras-chave: carcaça, desempenho, enzimas, farelo de arroz integral, frangos de corte.

\section{ABSTRACT}

This experiment was conducted to determine the performance and carcass yeld of broilers fed diets based on increasing whole rice meal levels (WRM), with or without multienzyme complex supplementation. Nine hundred and sixty Cobb chicks, males and females, were allocated in a completely randomized design with eight treatments and six replicates with 20 birds. Four levels of WRM $(0 \%, 10 \%, 20 \%$ and $30 \%)$, with and without supplementation of a multienzyme complex composed of protease, pentosanase e phytase enzymes were used in the experiment. The diets had the same levels of energy, protein, calcium and phosphorus in all the treatments. With the use of increasing levels of whole rice meal, there was significant reduction $(P<0.01)$ in the feed intake, body weight and weight gain of the bird, however, the feed: gain ratio was not affected. The breast weight, breast yeld, carcass weight and thigh weight were also affected significantly $(P<0.01)$ by levels of addition of whole rice meal in the diet. The use of enzymes did not influence none of the evaluated parameters significantly $(P>0.05)$, however, in the diets supplemented with enzymes, the bio-economic index was $1.4 \%$ higher than the diets without supplementation.

Key words: carcass, performance, enzymes, whole rice meal, broilers.

\section{INTRODUÇÃO}

Considerando-se que, do custo total de produção, os gastos com alimentação representam cerca de 60-70\%, maior lucratividade está associada a formas alternativas para diminuir esses gastos (SAKOMURA, 1996). Um dos ingredientes alternativos é o farelo de arroz integral (FAI), que é um subproduto do beneficiamento do arroz contendo pericarpo, gérmen e pequenas quantidades de casca e arroz quebrado (EMBRAPA, 1985), no entanto, sua utilização em dietas de frangos de corte está limitada em função

\footnotetext{
${ }^{1}$ Graduando do curso de Medicina Veterinária, Centro de Ciências Rurais (CCR), Universidade Federal de Santa Maria (UFSM), RS. Bolsista da FAPERGS. Endereço: Avenida Itaimbé, 686, ap.32, 97050-330, Santa Maria, RS. E-mail: eliveltonbonato@bol.com.br. Autor para correspondência.

${ }^{2}$ Professor adjunto, Departamento de Zootecnia, CCR, UFSM,

${ }^{3}$ Acadêmicos do Curso de Medicina Veterinária, CCR, UFSM.

${ }^{4}$ Acadêmica do Curso de Zootecnia, CCR, UFSM.

${ }^{5}$ Zootecnista, Setor de avicultura, Departamento de Zootecnia, CCR, UFSM.
} 
da presença de polissacarídeos não amiláceos (PNA) e altos teores de ácido fítico.

A porcentagem de PNA do FAI é bastante alta, de 25\% segundo CANTOR (1995). Vários autores (KELSAI, 1978; FIALHO, 1991; TEIXEIRA, 1994 e DOMENE, 1996) apontam a presença de PNA no alimento, e conseqüente formação de gel no trato intestinal, como um dos fatores que afetam negativamente a absorção de minerais. A presença do ácido fítico mantém complexado aproximadamente $85 \%$ do fósforo do FAI (ROSTAGNO, 1998). Outros minerais tais como o cálcio, cobre, zinco, manganês, ferro e cobalto também são complexados na molécula de fitato, reduzindo a sua absorção (SEBASTIAN et al., 1996).

O emprego de preparados enzimáticos cada vez mais usuais no mercado tem apresentado bons resultados na redução de fatores antinutricionais encontrados nos grãos dos cereais utilizados nas dietas das aves (ROTTER et al., 1990, VÖLKER \& TÜLLER, 1993). As enzimas comercialmente produzidas a fim de aumentar a digestibilidade de nutrientes e melhorar a sua utilização são provenientes, geralmente de bactérias do gênero Bacillus sp ou fungos do gênero Aspergillus sp (FERKET, 1996).

SOTO-SALANOVA (1996) observou a manutenção do ganho de peso, com menor consumo e melhor conversão alimentar quando suplementou rações à base de milho e soja para frangos de corte com suplemento enzimático, indicando melhor digestibilidade dos nutrientes. LÓPEZ et al. (1978) observaram efeitos desfavoráveis sobre o ganho de peso de frangos de corte consumindo dietas com mais de $30 \%$ de farelo de arroz e isto foi atribuído, ao menor consumo e ao maior conteúdo de fibra bruta, lignocelulose e sílica na ração, o que diminuiu a digestibilidade. KRATZER \& PAYNE (1977) também verificaram efeitos desfavoráveis sobre o ganho de peso e a conversão alimentar de pintos em crescimento, com o aumento do nível de inclusão de farelo de arroz integral na ração de 0 a $60 \%$.

Objetivando estabelecer as relações entre o nível de inclusão de farelo de arroz integral (FAI) na dieta de frangos de corte, FIALHO \& LÓPEZ (1991) conduziram dois experimentos com níveis crescentes de $0,8,33,16,67$ e 25\% de FAI. A análise de regressão mostrou efeito quadrático para ganho de peso, enquanto a conversão alimentar apresentou apenas efeito linear negativo. Concluíram que o nível de inclusão de 19,6\% de FAI pode ser considerado o nível ótimo de inclusão na dieta, do ponto de vista de desempenho. SANTOS et al. (2001), trabalhando com níveis crescentes de FAI $(0,10,20$ e 30\%) e enzimas, observaram que houve um declínio linear no peso corporal da aves, à medida que foi aumentada a inclusão de FAI nas dietas.

GRAHAM \& INBORR (1993) observaram que a pentosanase é efetiva na degradação das paredes celulares, promovendo assim, maior liberação de nutrientes, o que explica o maior desempenho dos animais. As enzimas neste caso atuam hidrolisando os PNA, reduzindo seu peso molecular, promovendo deste modo, a redução da viscosidade do meio em que estes estão diluídos, melhorando a digestibilidade dos nutrientes e promovendo um melhor desempenho dos animais.

O objetivo deste trabalho foi determinar o desempenho e o rendimento de carcaça de frangos de corte alimentados com dietas contendo níveis crescentes de farelo de arroz integral (FAI), suplementadas ou não com enzimas.

\section{MATERIAL E MÉTODOS}

O trabalho foi conduzido no Setor de Avicultura do Departamento de Zootecnia da Universidade Federal de Santa Maria (UFSM - RS), no período compreendido entre 17/05 e 28/06/00. Foram utilizados 960 pintos da linhagem Cobb machos e fêmeas de um dia de idade, alojados em um galpão experimental dividido em boxes de $2,25 \mathrm{~m}^{2}$. O delineamento experimental utilizado foi o inteiramente casualizado com oito tratamentos $(0 \%, 10 \%, 20 \%$ e $30 \%$ com e sem enzima) e seis repetições (três de machos e três de fêmeas) com 20 aves cada.

$\mathrm{Na}$ primeira semana, os pintos foram alimentados por meio de comedouros do tipo bandeja sendo posteriormente substituídos por comedouros tipo tubular que permaneceram até o final do experimento. Também foram utilizados bebedouros do tipo pendular durante todo o experimento. Cada box foi equipado com uma fonte de aquecimento, durante os 19 dias de idade, e as cortinas permaneceram fechadas nas horas mais frias. Após este período, de acordo com a temperatura ambiente e o comportamento das aves, as cortinas foram abertas gradativamente. As aves receberam água e ração ad libitum durante todo o período experimental.

Foram utilizados três tipos de dietas fareladas, nas diferentes fases de criação: ração inicial (1-21 dias); crescimento (22-35 dias) e final (36-42 dias), apresentadas na tabela 1 . As dietas eram isonutritivas e foram formuladas seguindo as exigências nutricionais recomendadas por ROSTAGNO (2000). O complexo enzimático utilizado era composto pelas enzimas protease, pentosanase e fitase, sendo adicionado nas dietas à razão de $1 \mathrm{~kg} /$ ton, conforme as orientações do fabricante. 
Tabela 1 - Composição percentual e química das dietas experimentais usadas nas fases inicial (I), crescimento (C) e final (F)

\begin{tabular}{|c|c|c|c|c|c|c|c|c|c|c|c|c|}
\hline \multirow{3}{*}{ Item } & \multicolumn{12}{|c|}{ Níveis crescentes de farelo de arroz } \\
\hline & \multicolumn{3}{|c|}{0} & \multicolumn{3}{|c|}{10} & \multicolumn{3}{|c|}{20} & \multicolumn{3}{|c|}{30} \\
\hline & I & $\mathrm{C}$ & $\mathrm{F}$ & I & $\mathrm{C}$ & $\mathrm{F}$ & I & $\mathrm{C}$ & $\mathrm{F}$ & I & $\mathrm{C}$ & $\mathrm{F}$ \\
\hline \multicolumn{13}{|l|}{ Ingredientes } \\
\hline Milho & 58,4 & 62,2 & 67,3 & 47,69 & 51,7 & 56,77 & 37,02 & 41,18 & 46,26 & 26,35 & 30,66 & 35,7 \\
\hline $\begin{array}{l}\text { Farelo de soja- } \\
48\end{array}$ & 34,9 & 29,8 & 25,2 & 34,1 & 29,06 & 24,38 & 33,35 & 28,28 & 23,6 & 32,6 & 27,5 & 22,8 \\
\hline $\begin{array}{l}\text { Farelo de arroz } \\
\text { integral }\end{array}$ & -- & -- & -- & 10 & 10 & 10 & 20 & 20 & 20 & 30 & 30 & 30 \\
\hline Óleo de soja & 2,69 & 3,99 & 3,82 & 4,16 & 5,35 & 5,17 & 5,63 & 6,7 & 6,53 & 7,1 & 8,05 & 7,88 \\
\hline $\begin{array}{l}\text { Fosfato } \\
\text { bicálcico }\end{array}$ & 1,93 & 1,93 & 1,86 & 1,83 & 1,88 & 1,76 & 1,72 & 1,77 & 1,65 & 1,62 & 1,62 & 1,55 \\
\hline $\begin{array}{l}\text { Calcário } \\
\text { calcítico }\end{array}$ & 1,04 & 0,93 & 1,02 & 1,11 & 0,98 & 1,07 & 1,18 & 1,03 & 1,11 & 1,26 & 1,08 & 1,16 \\
\hline $\begin{array}{l}\text { Cloreto de } \\
\text { sódio }\end{array}$ & 0,5 & 0,45 & 0,4 & 0,5 & 0,45 & 0,4 & 0,5 & 0,45 & 0,4 & 0,5 & 0,45 & 0,4 \\
\hline $\begin{array}{l}\text { Premix- } \\
\text { vitamínico }\end{array}$ & 0,1 & 0,4 & 0,25 & 0,1 & 0,4 & 0,25 & 0,1 & 0,4 & 0,25 & 0,1 & 0,4 & 0,25 \\
\hline $\begin{array}{l}\text { Premix- } \\
\text { mineral }^{2}\end{array}$ & 0,1 & 0,1 & 0,1 & 0,1 & 0,1 & 0,1 & 0,1 & 0,1 & 0,1 & 0,1 & 0,1 & 0,1 \\
\hline Areia & 0,1 & 0,1 & 0,1 & 0,1 & 0,1 & 0,1 & 0,1 & 0,1 & 0,1 & 0,1 & 0,1 & 0,1 \\
\hline Banox & 0,02 & 0,03 & -- & 0,02 & 0,03 & -- & 0,02 & 0,03 & -- & 0,02 & 0,03 & -- \\
\hline \multicolumn{13}{|c|}{ Valores calculados } \\
\hline $\begin{array}{l}\text { Proteína bruta } \\
(\%)\end{array}$ & 21,9 & 19,8 & 18 & 21,87 & 19,8 & 18 & 21,87 & 19,8 & 18 & 21,87 & 19,8 & 18 \\
\hline $\begin{array}{l}\text { Energia metab. } \\
(\mathrm{kcal} / \mathrm{kg})\end{array}$ & 3000 & 3100 & 3150 & 3000 & 3100 & 3150 & 3000 & 3100 & 3150 & 3000 & 3100 & 3150 \\
\hline Cálcio (\%) & 0,95 & 0,88 & 0,88 & 0,96 & 0,88 & 0,88 & 0,97 & 0,88 & 0,88 & 0,98 & 0,88 & 0,88 \\
\hline $\begin{array}{l}\text { Fósforo disp. } \\
(\%)\end{array}$ & 0,45 & 0,42 & 0,4 & 0,45 & 0,42 & 0,4 & 0,45 & 0,42 & 0,4 & 0,45 & 0,42 & 0,4 \\
\hline Arginina (\%) & 1,57 & 1,25 & 12,12 & 1,49 & 1,28 & 12,15 & 1,41 & 1,31 & 1,18 & 1,33 & 1,34 & 1,21 \\
\hline Lisina $(\%)$ & 1,08 & 0,99 & 0,88 & 1,08 & 1,01 & 0,89 & 1,08 & 1,02 & 0,9 & 1,08 & 1,03 & 0,91 \\
\hline Metionina (\%) & 0,43 & 0,35 & 0,35 & 0,43 & 0,35 & 0,35 & 0,43 & 0,35 & 0,35 & 0,43 & 0,35 & 0,35 \\
\hline Met+Cys (\%) & 0,78 & 0,62 & 0,57 & 0,78 & 0,62 & 0,57 & 0,78 & 0,62 & 0,57 & 0,78 & 0,62 & 0,57 \\
\hline Treonina $(\%)$ & 0,72 & 0,74 & 0,68 & 0,72 & 0,74 & 0,68 & 0,72 & 0,74 & 0,68 & 0,72 & 0,74 & 0,68 \\
\hline Triptofano (\%) & 0,25 & 0,25 & 0,23 & 0,25 & 0,25 & 0,23 & 0,26 & 0,25 & 0,23 & 0,26 & 0,25 & 0,23 \\
\hline
\end{tabular}

${ }^{1}$ Cada quilograma do produto contém: Vit. A 2.300.000UI, Vit. D $400.000 U I$, Vit. E 1.800mg, Vit. K3 300mg, Vit. B1 150mg, Vit. B2 $1.400 \mathrm{mg}$, Vit. B12 3.500mcg, Ácido Pantotênico 2.000mg, Ácido Fólico 150mg, Ácido Nicotinico 7.000mg, Piridoxina 250mg, Biotina 20mg, Colina $125 \mathrm{~g}$, Veículo q.s.p $1.000 \mathrm{~g}$.

${ }^{2}$ Cada quilograma do produto contém: Ferro $35.000 \mathrm{mg}$, Cobre 50.000 mg, Manganês $35.000 \mathrm{mg}$, Zinco 30.000 mg, Iodo 600 mg, Selênio 90 mg, Antioxidante $20 \mathrm{~g}$, Veículo q.s.p $1000 \mathrm{~g}$.

Efeito linear $\mathrm{Y}=0,474775-0,001643 \quad\left(\mathrm{R}^{2}=0,16\right)$

As aves e as sobras de ração foram pesadas ao final de cada fase de criação. Os parâmetros analisados foram peso corporal, ganho de peso, consumo de ração, conversão alimentar, índice bioeconômico e características de carcaça. Aos 42 dias de idade, foram selecionadas duas aves por repetição, que apresentassem o peso vivo médio da respectiva unidade experimental. As 96 aves dos respectivos tratamentos foram abatidas por sangria na artéria jugular, depenadas e evisceradas. Para resfriamento, as carcaças foram imersas em um tanque com gelo e água (chiller), permanecendo por aproximadamente 30 minutos. Após a retirada do chiller, as aves foram suspensas por um tempo aproximado de 3 minutos pela cabeça, para o escorrimento da água absorvida em excesso e, posteriormente, efetuou-se a pesagem das carcaças inteiras.

O rendimento da carcaça foi determinado pela relação entre o peso da ave desprovida de sangue, penas e vísceras e o peso vivo no abate. Considerou- 
se como gordura abdominal aquela depositada na região abdominal, próxima a "Bursa de Fabrícius" e a gordura aderida à moela, as quais foram retiradas manualmente. $O$ peito e as coxas foram separados da carcaça com pele e osso. O rendimento do peito e das coxas foi obtido pela relação entre os respectivos pesos e o peso vivo no abate.

Todos os parâmetros foram submetidos à análise de variância pelo programa SAS (1996). Para os parâmetros que apresentaram na análise de variância valores de $\mathrm{F}$ significativo $(\mathrm{P}<0,05)$, foi aplicado o Teste de Tukey ( $5 \%$ ) para comparar as médias.

\section{RESULTADOS E DISCUSSÃO}

A adição do complexo enzimático nas dietas não melhorou nenhum dos parâmetros avaliados $(\mathrm{P}>0,05)$. A inclusão de diferentes níveis de FAI acarretou um decréscimo no consumo de ração, no peso corporal e no ganho de peso das aves, sem a conversão alimentar ser alterada. Estes resultados foram observados tanto na ausência quanto na presença de enzimas exógenas (Tabela 2).

Resultados semelhantes foram encontrados por LÓPEZ et al. (1978), CARRION \& LÓPEZ (1989), SOUZA \& LÓPEZ (1994) e SANTOS et al. (2001), que observaram que quanto maior o nível de inclusão de FAI na dieta, menor o consumo alimentar e o peso corporal das aves. Segundo LÓPEZ et al. (1978) isto é atribuído ao menor consumo e ao maior conteúdo de fibra bruta, lignocelulose e sílica na ração.

SANTOS et al. (2001) também não verificaram resultados significativos da enzima sobre a conversão alimentar quando suplementaram dietas à base de farelo de arroz integral para frangos de corte. No entanto, SCHANG (1996), SOTO-SALANOVA (1996) e FIGUEIREDO et al. (1998) observaram diferenças $(\mathrm{P}<0,05)$ na conversão alimentar pela aplicação de enzimas exógenas em dietas para frangos de corte.

Para o índice bio-econômico, a análise estatística não detectou diferença significativa $(\mathrm{P}>0,05)$ para os fatores analisados e para a interação (FAI x Enzima). Apesar de não se verificar efeito significativo de enzimas, as rações suplementadas com o complexo multienzimático, promoveram um IBE 1,4\% superior em relação as dietas não suplementadas.

Na tabela 3, são apresentadas as médias de rendimento de carcaça (\%), rendimento de peito em relação ao peso vivo (\%), rendimento de coxa em relação ao peso vivo (\%), e relação gordura abdominal e peso vivo com os resultados da análise de variância e as equações de regressão em função dos níveis de inclusão de farelo de arroz integral.

Foi observada diferença significativa $(\mathrm{P}<0,01)$ para o farelo de arroz no parâmetro rendimento de peito, onde o tratamento com $0 \%$ de FAI apresentou maior peso em relação ao tratamento com $30 \%$ de FAI,

Tabela 2 - Resultados das médias de Peso Corporal (PC), Ganho de Peso (GP), Consumo de Ração (CR), Conversão Alimentar (CA), Índice bio-econômico, análise de variância na fase de 1 - 42 dias de idade e equações de regressão em função dos níveis de inclusão de Farelo de Arroz Integral (FAI).

\begin{tabular}{|c|c|c|c|c|c|}
\hline \multirow[b]{2}{*}{ Tratamentos } & $\mathrm{PC}(\mathrm{kg})^{1}$ & $\mathrm{GP}(\mathrm{kg})^{2}$ & $\mathrm{CR}(\mathrm{kg})^{3}$ & $\mathrm{CA}$ & IBE \\
\hline & \multicolumn{5}{|c|}{ Efeito dos níveis de farelo de arroz integral (FAI) } \\
\hline $0 \%$ & $2,250 \mathrm{a}$ & $2,205 \mathrm{a}$ & $4,463 \mathrm{a}$ & 2,02 & 0,292 \\
\hline $10 \%$ & $2,203 \mathrm{a}$ & $2,159 \mathrm{a}$ & $4,306 \mathrm{ab}$ & 2,01 & 0,318 \\
\hline $20 \%$ & $2,107 \mathrm{ab}$ & $2,083 \mathrm{ab}$ & $4,145 \mathrm{bc}$ & 1,99 & 0,277 \\
\hline \multirow[t]{2}{*}{$30 \%$} & $1,992 \mathrm{~b}$ & $1,969 \mathrm{~b}$ & $3,955 \mathrm{c}$ & 1,99 & 0,268 \\
\hline & \multicolumn{5}{|c|}{ Efeito da enzima } \\
\hline S/ enzima & 2,152 & 2,119 & 4,255 & 2,01 & 0,287 \\
\hline \multirow[t]{2}{*}{$\mathrm{C} /$ enzima } & 2,124 & 2,090 & 4,179 & 2,00 & 0,291 \\
\hline & \multicolumn{5}{|c|}{ Valores de F } \\
\hline FAI & $6,91 * *$ & $5,68 * *$ & $7,31 * *$ & 0,60 & 0,82 \\
\hline Enzima & 0,40 & 0,44 & 0,90 & 0,15 & 0,24 \\
\hline FAI X Enzima & 0,37 & 0,88 & 0,40 & 3,35 & 1,59 \\
\hline $\mathrm{CV}(\%)$ & 7,01 & 7,10 & 6,62 & 3,48 & 28,97 \\
\hline
\end{tabular}

Médias seguidas de mesma letra na coluna não diferem entre si.

$* *(\mathrm{P}<0,01)$

${ }^{1}$ Efeito linear $\mathrm{Y}=2,268075-0,008676\left(\mathrm{R}^{2}=0,32\right)$

${ }^{2}$ Efeito linear $\mathrm{Y}=2,216575-0,007828\left(\mathrm{R}^{2}=0,27\right)$

${ }^{3}$ Efeito linear $\mathrm{Y}=4,470008-0,168575\left(\mathrm{R}^{2}=0,35\right)$ 
Tabela 3 - Médias de Rendimento de Carcaça (RC), Rendimento de Peito em relação ao Peso Vivo (RP/PV), Rendimento de Coxa em relação ao Peso Vivo (RCO/PV), Relação entre Gordura Abdominal com Peso Vivo (GA/PV), análise de variância e equações de regressão em função dos níveis de inclusão de Farelo de Arroz Integral (FAI).

\begin{tabular}{|c|c|c|c|c|}
\hline \multicolumn{5}{|c|}{ Parâmetros avaliados } \\
\hline Tratamentos & $\mathrm{RC}(\%)$ & $\mathrm{RP} / \mathrm{PV}(\%)^{1}$ & $\mathrm{RCO} / \mathrm{PV}(\%)$ & $\mathrm{GA} / \mathrm{PV}(\%)$ \\
\hline \multicolumn{5}{|c|}{ Efeito dos níveis de farelo de arroz integral (FAI) } \\
\hline $0 \%$ & 81,78 & $21,21 \mathrm{a}$ & 21,44 & 1,89 \\
\hline $10 \%$ & 80,37 & $20,74 \mathrm{ab}$ & 21,13 & 2,09 \\
\hline $20 \%$ & 80,49 & $20,04 \mathrm{ab}$ & 21,53 & 2,16 \\
\hline $30 \%$ & 80,52 & $19,66 \mathrm{~b}$ & 21,06 & 2,10 \\
\hline \multicolumn{5}{|c|}{ Efeito de enzima } \\
\hline Sem adição de enzima & 80,66 & 20,39 & 21,13 & 2,11 \\
\hline Com adição de enzima & 80,92 & 20,42 & 21,44 & 2,02 \\
\hline \multicolumn{5}{|c|}{ Valores de F } \\
\hline Níveis de FAI & 1,50 & $4,47 * *$ & 0,77 & 1,12 \\
\hline Enzima & 0,24 & 0,01 & 1,49 & 0,84 \\
\hline Níveis de FAI x Enzima & 0,45 & 0,44 & 0,74 & 0,19 \\
\hline C.V. $(\%)$ & 2,31 & 5,56 & 4,26 & 17,89 \\
\hline
\end{tabular}

Médias seguidas de mesma letra na coluna não diferem entre si.

$* *(\mathrm{P}<0,01)$.

${ }^{1}$ Efeito linear $\mathrm{Y}=21,211583-0,533417 \quad\left(\mathrm{R}^{2}=0,24\right)$.

os demais tratamentos não diferiram entre si. Com o aumento da inclusão de FAI nas dietas, houve uma redução significativa $(\mathrm{P}<0,01)$ no peso da carcaça, peso de peito e peso de coxa (Tabela 4).

ZANELLA (1998) testando a suplementação enzimática em dietas a base de milho e sojas processadas também não encontrou diferença significativa em nenhum dos parâmetros de carcaça. Com relação ao efeito da suplementação de enzimas, WYATT et al. (1997) ao suplementarem dietas a base de milho e soja com Avizyme 1500âa, também não verificaram diferenças no rendimento de carcaça.

Tabela 4 - Médias de Peso da Carcaça (PC), Peso de Peito (PP), Peso de Coxa (PCO), Peso da Gordura Abdominal (GA), resultados da análise de variância e equações de regressão em função dos níveis de inclusão de Farelo de Arroz Integral (FAI)

\begin{tabular}{|c|c|c|c|c|}
\hline Tratamentos & $\mathrm{PC}(\mathrm{kg})^{1}$ & $\mathrm{PP}(\mathrm{kg})^{2}$ & PCO $(k g)^{3}$ & $\mathrm{GA}(\mathrm{kg})$ \\
\hline \multicolumn{5}{|c|}{ Efeito dos níveis de farelo de arroz integral (FAI) } \\
\hline $0 \%$ & $1,80 \mathrm{a}$ & $0,47 \mathrm{a}$ & $0,47 \mathrm{a}$ & 0,042 \\
\hline $10 \%$ & $1,74 \mathrm{a}$ & $0,45 \mathrm{ab}$ & $0,46 \mathrm{ab}$ & 0,046 \\
\hline $20 \%$ & $1,67 \mathrm{ab}$ & $0,42 \mathrm{ab}$ & $0,45 \mathrm{ab}$ & 0,045 \\
\hline $30 \%$ & $1,62 \mathrm{~b}$ & $0,39 \mathrm{c}$ & $0,43 \mathrm{~b}$ & 0,042 \\
\hline \multicolumn{5}{|c|}{ Efeito de enzima } \\
\hline S/ enzima & 1,70 & 0,43 & 0,45 & 0,44 \\
\hline $\mathrm{C} /$ enzima & 1,71 & 0,43 & 0,45 & 0,42 \\
\hline \multicolumn{5}{|c|}{ Valores de F } \\
\hline FAI & $4,32 * *$ & $10,98 * *$ & $2,78 * *$ & 0,71 \\
\hline Enzima & 0,05 & 0,04 & 0,31 & 0,61 \\
\hline FAI x Enzima & 0,33 & 0,95 & 0,15 & 0,21 \\
\hline C.V. $(\%)$ & 7,62 & 7,49 & 9,39 & 18,11 \\
\hline
\end{tabular}

Médias seguidas de mesma letra na coluna não diferem entre si.

$* *(\mathrm{P}<0,01)$

${ }^{1}$ Efeito linear $\mathrm{Y}=2,214300-0,006816 \quad\left(\mathrm{R}^{2}=0,19\right)$

${ }^{2}$ Efeito linear $\mathrm{Y}=0,467975-0,002453 \quad\left(\mathrm{R}^{2}=0,43\right)$

${ }^{3}$ Efeito linear $\mathrm{Y}=0,474775-0,001643 \quad\left(\mathrm{R}^{2}=0,16\right)$ 


\section{CONCLUSÕES}

A utilização do complexo multienzimático não proporciona melhora significativa em nenhum dos parâmetros analisados. Com o aumento dos níveis de inclusão de farelo de arroz integral nas dietas, as aves obtêm menor ganho de peso, consomem uma menor quantidade de ração, apresentam menor peso corporal e menor rendimento de peito, bem como menor peso da carcaça, menor peso de peito e menor peso de coxa.

\section{REFERÊNCIAS BIBLIOGRÁFICAS}

CANTOR, A. Enzimas usadas na Europa, Estados Unidos e Ásia. Possibilidades para uso no Brasil. In: RONDA LATINOAMERICANA DE BIOTECNOLOGIA, 1995, Curitiba, PR. Anais... Curitiba : n.i., 1995. p.31-42.

CARRION, J.G.; LÓPEZ, J. O farelo de arroz integral em 1.Desempenho e produtividade animal. Revista Brasileira de Zootecnia, Viçosa, v.18, n.4, p.320-326, 1989.

DOMENE, S.M.A. Estudo do valor nutritivo mineral do farelo de arroz. Utilização do zinco, ferro, cobre e cálcio pelo rato em crescimento. 1996. 104f. Tese (Doutorado em Ciência da Nutrição) - UNICAMP.

EMBRAPA. Tabelas de composição química e energética de alimentos para aves e suínos. 2.ed. Concórdia, SC : CNPSA, 1985. 29p.

FERKET, P. Enzymes offer way to reduce waste, improve performance. Feedstuffs, v.22, p.30-34, 1996.

FIALHO, F.B. Disponibilidade de manganês do farelo de arroz para frangos de corte. 1991. 156f. Dissertação (Mestrado em Nutrição Animal) - Universidade Federal do Rio Grande do Sul.

FIALHO, F.B.; LÓPEZ, J. Influência de níveis de farelo de arroz integral no desempenho de frangos de corte. In : REUNIÃO ANUAL DA SBZ, 1991, João Pessoa, PB. Anais... João Pessoa, n.i, 1991. p.338.

FIGUEIREDO, A.N. et al. Efeito da adição de enzimas em dietas à base de milho e tipos de soja sobre o desempenho de frangos de corte. In: CONFERÊNCIA APINCO DE CIÊNCIAS E TECNOLOGIAS AVÍCOLAS, 1998, Campinas, SP. Anais... Campinas : Facta, 1998. p.36.

GRAHAM,H.; INBORR, J. Enzimas para piensos - modo de actuacion y aplicacion en piensos avicolas termoprocessados. In: SEMINARIO AMANDUS KAHL, 1993, Hannover. Proceedings... Hannover, n.i.,1993. p.1-8.

KELSAY, J.L. A review of research on effects of fiber intake on mam. American Jounal of Clinical Nutrition, v.31, n.1, p.142-159, 1978.

KRATZER, F.H.; PAYNE, C.G. Effect of autoclaving, hotwater treating, parboiling and addition os ethoxiquin on the value of rice bran as a dietary ingredient of chickens. Britannic Poultry Science, Abingdon, v.18, p.475-82,1977.

LÓPEZ, J. et al. Farelo desengordurado de arroz na alimentação de pintos. Revista Brasileira de Zootecnia, Viçosa , v.7, n. 1, p.43-52, 1978 .

ROSTAGNO, HS. Tabelas brasileiras para aves e suínos Composição de alimentos e exigências nutricionais, Viçosa, MG : COPASUL, 2000. 141p.

ROTTER, B.A. et al. Influence of enzyme supplementation on the bioavailable energy of barley. Poultry Science, v.69, n.7, p.1174-1181, 1990.

SAKOMURA, N.K. Estudo do valor nutricional das sojas integrais processadas $e$ de sua utilização na alimentação de frangos e poedeiras. 1996. 178f. Tese (Livre Docente) -Faculdade de Ciências Agrárias e Veterinárias, Universidade Estadual Paulista.

SANTOS, R. et al. Efeito da diminuição dos nívies de cálcio e fósforo em dietas com farelo de arroz integral e enzimas sobre o desempenho de frangos de corte. In: CONFERÊNCIA APINCO, 2001, Campinas, SP. Revista Brasileira de Ciência Avícola, Suplemento 3, p.31, 2001.

SAS Statistical Analisysis System User's Guide. Stat, 2.ed. Cary : SAS Institute, 1997. 456p.

SCHANG, M.J. O uso da enzima vegpro em dietas para frangos em crescimento. In: RONDA LATINO AMERICANA DE Biotecnologia, 6., 1966, Curitiba. Anais... Curitiba : ALLTECH, 1996. p.71-77.

SEBASTIAN, S. et al. The effects of supplemental microbial phytase on the performance and utilization of dietary calcium, phosphorus, copper, and zinc in broiler chickens fed cornsoybeans diets. Poultry Science, v.75, n.2, p.729-736, 1996.

SOTO-SALANOVA M. The use of enzymes to improve the nutricional value of corn-soy diets for poultry and swine. In: SIMPOSIO LATINO-AMERICANO DE NUTRIÇAO DE SUINOS E AVES, 1996, Campinas. Proceedings... Campinas: n.i., 1996 . p.1-13.

SOUZA, G.A.; LÓPEZ, J. Farelo de arroz integral com fonte de fósforo em rações para frangos de corte. 1. desempenho e produtividade animal. Revista Brasileira de Zootecnia, v.23, n.1, p.73- 84, 1994.

TEIXEIRA, A.S. Exigências nutricionais de zinco e sua biodisponibilidade em sulfatos e óxidos de zinco para pintos de corte. 1994. 172 f. Tese (Doutorado em Produção Animal) - Universidade Federal do Rio Grande do Sul.

VÖLKER, L.; TÜLLER, R. Effect of Roxazyme G supplementation to wheat - and wheat/barley-based diets on the performance of growing turkeys. In: ENZYMES IN ANIMAL NUTRITION SYMPOSIUM, 1993, Kartause Ittingen. Proceedings... Zurich, 1993. p.141-144.

WYATT, C.L.; MORAN, E.; BERDORD, M.R. Utilizing feed enzymes to enhance the nutritional value of corn based broilers diets. In: POULTRY SCIENCE ASSOCIATION ANNUAL MEETING, 86., 1997, Louisvile. Proceedings... Louisvile: Poultry Science Association, 1997. 154p.

ZANELLA, I. Suplementação enzimática em dietas a base de milho e sojas processadas sobre a digestibilidade de nutrientes e desempenho de frangos de corte. 1998. 187f. Tese (Doutorado em Zootecnia) - Faculdade de Ciências Agrárias e Veterinárias, Universidade Estadual Paulista. 